\title{
HUBUNGAN LAMA DAN FREKUENSI PENGGUNAAN GADGET DENGAN PERKEMBANGAN SOSIAL ANAK PRA SEKOLAH DI TK ISLAM AL IRSYAD 01 CILACAP
}

\author{
Sujianti ${ }^{1)}$ \\ E-mail address: umiyahyasuji@gmail.com
}

\begin{abstract}
The use of gadgets among children is increasingly alarming and certainly has a negative impact on growth and development. The ease of accessing various information and technology media causes children to become lazy to move and move. They prefer to sit quietly in front of the gadget and enjoy the world in the gadget. Gradually forget the pleasure of playing with family members. This certainly has a negative impact on children's social development.

This study aims to determine the relationship between the duration and frequency of gadget use with the social development of preschool children.

The design of this study was descriptive correlative with a cross sectional approach to 53 mothers who had preschool aged children (5-6 years) in Al Irsyad Islamic Kindergarten 01 Cilacap with simple random sampling technique. The type of primary data uses children's social development questionnaire. Data were analyzed by univariate and bivariate with Chi Square test..

From 53 respondents, the most normal gadget usage time ( $<60$ / day) 33 (62.3\%), the most normal frequency $44(83.1 \%)$, the best social development $27(50.9 \%)$.

There is no relationship between the duration of using gadgets and the social development of preschoolers.(p:0.577). There is no relationship between frequency of using gadgets and the social development of preschoolers.(p:1.000)
\end{abstract}

Keywords: duration and frequency; social development; gadget; preschool

${ }^{1)}$ STIKES Al-Irsyad Al-Islamiyyah Cilacap

\section{Pendahuluan}

Perkembangan tehnologi
gadget/ smartphone menunjukkan
perkembangan jaringan internet yang
sangat cepat dimulai dari jaringan
2G, 3G, bahkan sekarang sudah diterapkan 4G Long Term Evolution (LTE). Secara teoritis LTE memiiki kemampuan memberikan kecepatan dalam hal transfer data, sehingga kecepatan akses yang tinggi memberikan kemudahan kepada pengguna smarphone dalam mendapatkankenyamanan berinternet. (Marsal A \& Hidayati F, 2017)

Dalam era globalisasi ini, anakanak lebih banyak menggunakan waktunya untuk bermain gadget dibandingkan dengan melakukan kegiatan fisik bersama teman. (Lisiswanti R \& Nabila SI, 2017). Penggunaan gadget pada anak sudah menjadi hal yang biasa, bahkan Indonesia adalah salah satu negara 
yang menjadi pengguna gadget terbesar. Berdasarkan penelitian yang dilakukan oleh Ismanto dan Onibala menunjukkan bahwa anak-anak yang terbiasa bermain gadget, maka mereka akan lebih banyak menghabiskan waktu untuk hal itu. (Laili U, 2017). Berdasarkan penelitian yang dilakukan oleh Rideout (2016) diketahui bahwa Indonesia adalah negara yang memiliki pengguna sosial media yang paling aktif di Asia. Indonesia memiliki $79,7 \%$ user aktif di sosial media mengalahkan Filipina 78\%, Malaysia 72\%, Cina 67\%. Di Indonesia penggunaan media gadget pada anak berusia 5 tahun yaitu $38 \%$ pada tahun 2011, dan meningkat menjadi $72 \%$ pada tahun 2013, pada tahun 2015 ada peningkatan yaitu $80 \%$. Anak banyak menggunakan gadget sebagai sarana bermain, $23 \%$ orang tua yang memiliki anak berusia 5 tahun mengaku bahwa anak-anak mereka gemarmenggunakan gadget, sedangkan dari $82 \%$ orang tua melaporkanbahwa mereka online setidaknya sekali dalam seminggu (Rideout, 2016 dalam Gunawan MAA, 2017)

Penelitian yang dilakukan oleh Delima, (2015) diperoleh hampir semua orang tua $94 \%$ menyatakan bahwa anak mereka biasa menggunakan perangkat teknologi untuk bermain game, $63 \%$ anak menghabiskan waktu maksimum 30 menit untuk sekali bermain game, sementara $15 \%$ orang tua menyatakan bahwa anak bermain game selama 30 sampai 60 menit dan sisanya dapat berinteraksi dengan sebuah game lebih dari satu jam (Yusmi, 2015)

Perilaku anak dalam menggunakan gadget memiliki dampak positif maupun negatif. Dampak positif dari penggunaan gadgte diantaranya memudahkan anak dalam mengasah kreativitas dan kecerdasan anak seperti adanya aplikasi mewarnai, membaca dan menulis yang menarik karena dilengkapi dengan gambar. Anak-anak tidak memerlukan tenaga dan waktu yang lebih untuk belajar membaca dan menulis di buku atau kertas. (Novitasari w \& Khotimah N, 2016)

Dampak negatif penggunaan gadget dalam waktu yang lama merupakan kebiasaan buruk dan akan berdampak kepada kesehatan dari anak tersebut, termasuk membuat pola hidup anak yang lebih sering duduk dan makan makanan cepat saji yang berdampak meningkatnya risiko penurunan akademik, obesitas dan depresi. Beberapa penelitian menyatakan bahwa screen time atau lamanya melihat layar monitor serta penggunaan media elektronik mempunyai hubungan dengan penurunan lama tidur, terlambatnya waktu tidur dan gangguan tidur pada anak ainnya. (Yland J, Guan S, Emanuele E, Hale L, 2015). Penggunaan gadget dikalangan anakanak semakin memprihatinkan dan tentu memiliki dampak negatif terhadap tumbuh kembang. (Warisyah Y, 2015). Kemudahan mengakses berbagai media informasi dan tehnologi, menyebabkan anak-anak 
menjadi malas bergerak dan beraktivitas. Mereka lebih memilih duduk diam di depan gadget dan menikmati dunia yang ada di dalam gadget tersebut. Lambat laun telah melupakan kesenangan bermain dengan anggota-anggota keluarganya. Hal ini tentunya berdampak buruk terhadap perkembangan sosial anak. (Novitasari w \& Khotimah N, 2016)

Hasil survey yang telah dilakukan peneliti di TK Islam Al Irsyad 01 Cilacap pada tanggal 25 Januari 2018 terhadap 7 orang tua siswa yang berusia 5 tahun dengan hasil semua telah menggunakan gadget, dimana yang 5 anak masih menggunakan gadgetmilik orang tuanya sedangkan yang 2anak menggunakan gadget milik sendiri. Darikeseluruhan orang tua tidak ada pengawasan atau aturan khusus dalam penggunaan gadget kecuali batas atau lama penggunaan. Kapasitas penggunaan rata rata 1-2 kali/ hari, lamanya 1-2 jam/hari, aplikasi yang digunakan rata-rata menggunakangame dan youtube. Dari 7 anak tersebut mereka mulai menggunakan gadget rata rata dari usia 3 tahun. (Al Fitri S, 2018).

\section{Metode Penelitian}

Penelitian ini menggunakan jenis penelitian deskriptif korelatif. dengan pendekatan cross sectional. Subyek penelitian ini adalah ibu anak pra sekolah usia 5-6 tahun yang menggunakan gadget. Pada penelitian ini yang menjadi populasi target adalah semua orang tua anak pra sekolah usia 5-6 tahun yang menggunakan gadget tahun 2018 sebanyak 212. Teknik yang digunakan dalam pengambilan sampel adalah simple random sampling. Setelah menggunakan rumus, besar sampel menjadi 50 orang.

Pengumpulan data primer untuk mengetahui lama penggunaan gadget dan perkembangan sosial anak prasekolah dilakukan dengan menyebar kuesioner kepada ibu anak pra sekolah usia 5 tahun. Kuesioner perkembangan sosial anak pra sekolah menggunakan kuesioner dari Gunawan MAA (2017) yang telah di uji reliabilitas menggunakan Alpha Cronbachdengan nilai sebesar 0.768 dan uji validitas menggunakan rumus Product Moment Pearsondengan $\mathrm{r}$ tabel $=0.361$ dan $\mathrm{r}$ hitung 0.515-1. Data dianalisis secara univariat dan bivariat dengan uji Chi Square.

\section{HASIL DAN PEMBAHASAN}

Tabel 1 Distribusi Frekuensi Karakteristik Ibu yang memiliki anak usia prasekolah

\begin{tabular}{lcc}
\hline Variabel & $\begin{array}{c}\text { Frekuens } \\
\mathbf{i}\end{array}$ & $\begin{array}{c}\text { Persentase } \\
(\boldsymbol{\%})(\mathbf{n}=\mathbf{5 3})\end{array}$ \\
\hline Usia & 6 & 11 \\
$\leq 30$ tahun & 68 & 89 \\
$>30$ tahun & 48 & 28 \\
\hline $\begin{array}{l}\text { Pendidikan } \\
\text { Menengah } \\
\text { (SMA/SMK) }\end{array}$ & 15 & 72 \\
$\begin{array}{l}\text { Tinggi } \\
\text { (Diploma- }\end{array}$ & 38 & \\
Sarjana) & & 55 \\
\hline $\begin{array}{l}\text { Pekerjaan } \\
\text { Bekerja } \\
\text { Ibu Rumah } \\
\text { Tangga (IRT) }\end{array}$ & 29 & \\
\hline
\end{tabular}




\begin{tabular}{lll}
\hline Jumlah Anak & & \\
$\leq 2$ orang & 41 & 77 \\
$>2$ orang & 12 & 23 \\
\hline Tipe & & \\
Keluarga & & 100 \\
Nuclear & 53 & \\
Family & & 0 \\
Extended & 0 & \\
Family & &
\end{tabular}

Berdasarkan tabel 1 diketahui bahwadari 53 responden karakteristik ibu berdasarkan usia paling banyak usia > 30 tahun sebanyak 48 (89\%), pendidikan $\mathrm{ibu}$ terbanyak tingkat menengah (SMA-Diploma) sebanyak 38 (72\%), sebagian besar ibu bekerja sebanyak 29 (55\%), memiliki jumlah anak $\leq 2$ terbanyak $\leq 41(77 \%)$ dan seluruh responden memiliki tipe keluarga inti (nuclear family) sebanyak 53 (100\%).

Tabel 2. Distribusi frekuensi lama penggunaan gadget pada anak prasekolah

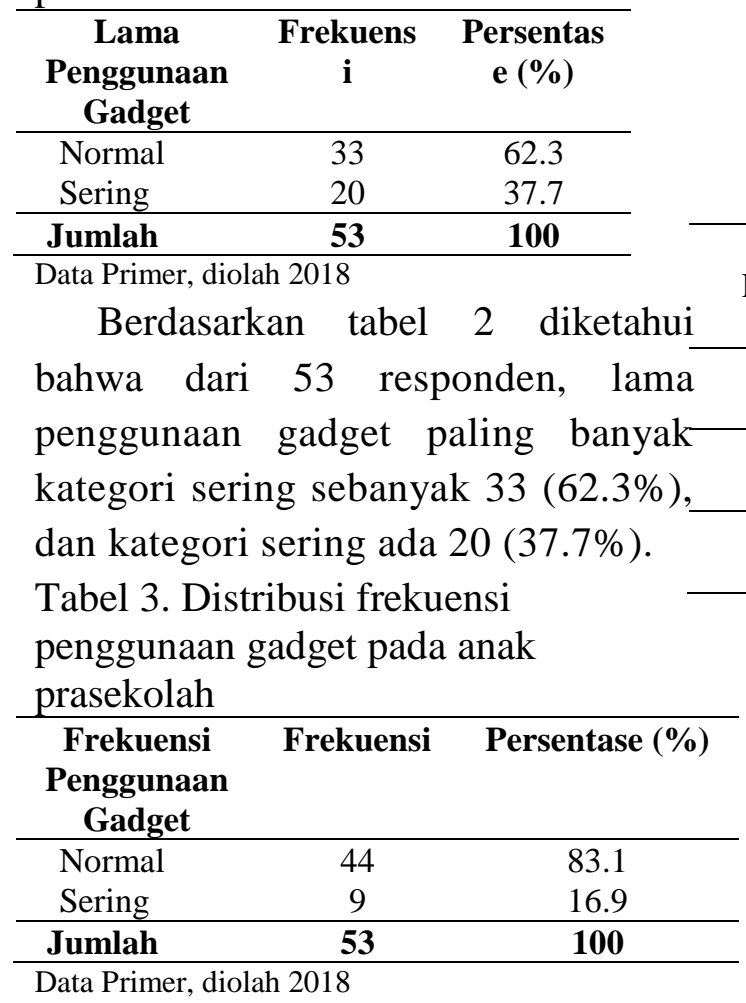

Tabel 5. Hubungan antara lama penggunaan gadget dengan perkembangan sosial pada anak prasekolah

\begin{tabular}{cccc}
$\begin{array}{c}\text { Lama } \\
\text { Penggunaan } \\
\text { Gadget }\end{array}$ & Baik & $\begin{array}{c}\text { Kurang } \\
\text { Baik }\end{array}$ & Jml \\
\cline { 2 - 3 } Normal & $\begin{array}{c}18(54.5 \\
\%)\end{array}$ & $\begin{array}{c}15 \\
(45.5 \%)\end{array}$ & 33 \\
\hline Sering & $9(45 \%)$ & $\begin{array}{c}11 \\
(55 \%)\end{array}$ & 20 \\
\hline \multicolumn{4}{c}{$p$ value $=0.577, \alpha=0.05, \mathrm{CI}=95 \%$} \\
OR $=1.467$
\end{tabular}

Berdasarkan tabel 5, hasil analisis hubungan antara lama penggunaan gadget dengan perkembangan sosial anak prasekolah diperoleh bahwa ada 11 anak (55\%) yang penggunaan gadgetnya sering berisiko mengalami perkembangan sosial yang kurang 
baik. Sedangkan diantara lama penggunaan gadget yang normal, ada 15 (45.5\%) mengalami perkembangan sosial yang kurang baik. Hasil uji statistik diperoleh nilai $\mathrm{P}=0.577$ $(\mathrm{P}>0.05)$ maka dapat disimpulkan tidak ada perbedaan proporsi perkembangan sosial antara lama penggunaan gadget yang normal dan sering (tidak ada hubungan yang signifikan antara lama penggunaan gadget dengan perkembangan sosial). Dari hasil analisis diperoleh pula nilai $\mathrm{OR}=$ 1.467, artinya anak yang lama menggunakan gadget $>60$ '/hari (sering) mempunyai peluang $1.467 \mathrm{kali}$ untuk mengalami perkembangan sosial kurang baik dibanding anak yang lama penggunaan gadgetnya normal.

Tabel 6. Hubungan antara frekuensi penggunaan gadget dengan perkembangan sosial pada anak prasekolah

\begin{tabular}{cccc}
\hline $\begin{array}{c}\text { Frekuensi } \\
\text { Penggunaan } \\
\text { Gadget }\end{array}$ & Baik & $\begin{array}{c}\text { Kurang } \\
\text { Baik }\end{array}$ & Jml \\
\cline { 2 - 3 } Normal & $\begin{array}{c}22(50 \\
\%)\end{array}$ & $22(50 \%)$ & 44 \\
\hline Sering & $\begin{array}{c}5 \\
(55.6 \%)\end{array}$ & $4(44.4 \%)$ & 9 \\
\hline p value $=\begin{array}{c}1.000, \alpha=0.05, \mathrm{CI}=95 \% \\
\mathrm{OR}=0.800\end{array}$ & \\
\hline
\end{tabular}

Berdasarkan tabel 6, hasil analisis hubungan antara frekuensi penggunaan gadget dengan perkembangan sosial anak prasekolah diperoleh bahwa ada 4 (44.46\%) anak yang penggunaan gadgetnya sering berisiko mengalami perkembangan sosial yang kurang baik. Sedangkan diantara frekuensi penggunaan gadget yang normal, ada $22(50 \%)$ mengalami perkembangan sosial yang kurang baik. Hasil uji statistik diperoleh nilai $\mathrm{P}=1.000$ maka dapat disimpulkan tidak ada perbedaan proporsi perkembangan sosial antara frekuensi penggunaan gadget yang normal dan sering (tidak ada hubungan yang signifikan antara frekuensi penggunaan gadget dengan perkembangan sosial). Dari hasil analisis diperoleh pula nilai $\mathrm{OR}=$ 0.800artinya anak yang frekuensi menggunakan gadget lebih dari 1 kali dengan waktu penggunaan lebih dari 60 menit (kategori sering) mempunyai peluang 0.800 kali untuk mengalami perkembangan sosial kurang baik dibanding anak yang frekuensi penggunaan gadgetnya normal.

a. Karakteristik responden

\section{Usia}

Usia responden sebagian besar > 30 tahun artinya usia yang matang dan siap untuk memiliki anak. Orangtua yang memiliki anak di usia ini akan memberikan semua kebutuhan anaknya dalam segala aspek yaitu mengasihi dengan kasih sayang dan perhatian, mengasuh dengan memenuhi kebutuhan secara fisik dan mengasah kemampuan dan ketrampilan anak agar dapat berkembang secara optimal.

\section{Pendidikan}

Pendidikan responden paling banyak kategoti tinggi (diplomasarjana) sebesar 38 (72\%). Pengetahuan berkaitan dengan pendidikan dimana diharapkan 
seseorang dengan pendidikan tinggi, maka orang tersebut akan semakin luas pengetahuannya, begitu pula dalam memantau perkembangan dan pertumbuhan anaknya termasuk dalam masalah mental emosional (Pangestu, 2014).

\section{Pekerjaan}

Karakteristik responden paling banyak bekerja sebesar 29 (55\%). Ibu yang bekerja bekerja dapat menambah tingkat perekonomian keluarga. Keluarga dengan perekonomian yang tinggi dapat memenuhi kebutuhan yang diperlukan dalam memberikan lingkungan yang aman, nyaman dan memenuhi nutrisi untuk membantu mengoptimalkan perkembangan anak.

\section{Jumlah anak}

Karakteristik responden dalam jumlah anak paling banyak 41 (77\%) memiliki anak $\leq 2$ orang. Pengalaman pribadi seseorang akan berbeda, begitu pula cara mengasuh anak. Hal ini dikarenakan kebiasaan atau anggapan bahwa pola asuh anak itu sama sehingga dapat dijadikan pelajaran dalam mengasuh anak yang lainnya (Chikmah, 2018)

\section{Tipe keluarga}

Tipe keluarga responden semuanya adalah tipe keluarga inti artinya kondisi ini sangat menentukan pola asuh yang akanditerapkan orangtua terhadap anaknya. Pola asuh orangtua akan menentukan kepribadian dan perkembangan anak

\section{b. Lama Penggunaan Gadget}

Lama penggunaan gadget menunjukkan $20 \quad$ (37.7\%) menggunakan gadget dalam kategori sering ( $>60$ '/hari). Berdasarkan sudut pandang ilmu kesehatan jiwa, penggunaan gadget pada usia dini tidak disarankan karena dapat menyebabkan anak tidak dapat belajar untuk berkomunikasi dan bersosialisasi (Hidayati, 2013 dalam Chikmah 2018).

Terbatasnya respon anak karena penggunaan gadget akan mengganggu perkembangan, ketidakmampuan anak untuk bergaul dan beradaptasi karena anak tidak mampu menjalin emosi, alhasil anak tidak dapat merespon hal yang ada di sekelilingnya baik secara emosi maupun verbal (Wiguna, 2013). Menurut psikolog Jovita MF menyatakan "anak usia di bawah 5 tahun, boleh diberi gadget, akan tetapi harus diperhatikan durasi pemakaiannya. Anak boleh bermain tapi hanya setengah jam dalam satu minggu" (Widiawati \& Sugiman, 2014). Televisi, video, permainan elektronik dan program komputer (gadget) juga membantu perkembangan ketrampilan dasar, namun American Academy of Pediatricsmenyarankan orangtua untuk membatasi waktu anak bermain dengan media elektronik 
agar anak melakukan kegiatan lain seperti membaca, aktivitas fisik dan bersosialisasi dengan orang lain (Potter \& Perry, 2009 dalam Sapardi 2018).

\section{c. Frekuensi Penggunaan Gadget}

Frekuensi penggunaan gadget menunjukkan $9 \quad(16.97 \%)$ menggunakan gadget dalam kategori sering (lebih dari 1 kali sehari dengan waktu penggunaan lebih dari 60 menit). Frekuensi penggunaan gadget sangat mempengaruhi perilaku komunikasi individu. Kini gadget sudah menjadi media komunikasi pokok. Hal tersebut dibuktikan dengan kenyataan di lapangan. Semua orang pasti tidak bisa lepas dari gadget, baik dalam berkomunikasi ataupun sekedar mengunggah di media sosial. Hal tersebut memperlihatkan bahwa intensitas penggunaan gadget berpengaruh terhadap perubahan perilaku individu semikian juga pada balita (Gifary, 2009 dalam Chikmah 2018).

Anak-anak yang frekuensi penggunaan gadgetnya terlalu sering diklaim sering kehilangan kemampuan perubahan dasar dalam berkomunikasi yaitu memhamai ekspresi atau gesture yang menandai perubahan perasaan seseorang. Padahal kemampuan tersebut adalah salah satu modal penting saat berinterkasi langsung (Pangastuti R, 2017).

\section{d. Perkembangan sosial anak}

Perkembangan sosial anak terbanyak kategori baik 27 (50.9\%). Menurut Kozier (2011), Soetjiningsih (2015), Wong (2010) proses percepatan dan perlambatan tumbuh kembang anak dapat dipengaruhi oleh beberapa faktor diantaranya faktor keturunan (jenis kelamin, ras, suku bangsa, bawaan), faktor lingkungan meliputi lingkungan prenatal (gizi saat hamil, al kohol, posisi janin, penggunaan obat-obatan, kebiasaan merokok) dan lingkungan post natal (budaya, sosial ekonomi, nutrisi, posisi anak dalam keluarga, status kesehatan) serta faktor hormonal. Stres pada pada masa anak-anak. Pengaruh media massa memberi anak suatu cara untuk memperluas pengetahuan mereka tentang dunia tempat mereka hidup (Sapardi, 2018).

Sementara 26 perkembangan sosial anak kurang baik. Kemungkinan perkembangan sosial anak kurang baik dilihat dari karakteristik responden yang kebanyakan ibu bekerja diluar rumah sehingga tidak dapat memantau hal yang dilakukan oleh anaknya karena orangtua tidak menghabiskan waktu dengan anaknya. Selain itu kadangkala orang tua sengaja memberikan gadget kepada anak mereka agar anak tidak bermain di luar rumah dan bahkan tidak mengganggu 
aktivitas orangtua pada saat di rumah.

Hal ini akan membuat anak malas bergerak dan beraktivitas, kurang berinteraksi dengan lingkungannya dan menghambat proses sosialisasi anak karena anak asyik dengan gadgetnya dan kelamaan anak dapat merasa bergantung / kecanduan pada gadget tersebut sehingga akan mempengaruhi perkembangan anak menjadi kurang baik. (Sapardi, 2018).

\section{e. Hubungan antara lama penggunaan gadget dengan perkembangan sosial anak}

Orangtua harus mendampingi anaknya saat bermain gadget, selain itu penggunaan gadget jangan sampai menjauhkan anak dari bersosialisasi dengan lingkungan sekitarnya. Penggunaan aplikasi yang tepat untuk pendidikan anak sangat dianjurkan, tetapi jangan sampai salah pilih aplikasi. Orangtua membatasi penggunaan gadget pada anak tidak lebih dari 30 menit persatu kali bermain, jeda sejenak dengan berjalan, bergerak, ke toilet yang menggerakkan tubuh atau memandang ke arah jauh untuk relaxasi mata. (Wijanarko J, 2017).

Smartphone salah satu faktor yang mempengaruhi terhadap pola interaksi sosial anak pada anak balita karena menurut responden, smartphone menjadi magnet yang kuat dalam ingatan anak dan merupakan salah satu alat yang mempengaruhi anak memiliki sifat individual dan kurang peka terhadap lingkungan. Selain itu smartphone juga mengubah kebiasaan komunikasi anak dalam dalam berkomunikasi langsung menjadi serba menggunakan smartphone dan anak menghabiskan waktu untuk bermain menggunakan smartphone. (Marsal A \& Hidayati $\mathrm{F}$, 2017).

Tidak adanya hubungan antara lama penggunaan gadget dengan perkembangan sosial anak kemungkinan karena ada beberapa faktor yang mempengaruhi perkembangan anak, salah satunya adalah asah asih asuh. Berdasarkan data responden sebagian besar usia> 30 tahun, pendidikan tinggi, bekerja, jumlah anak $\leq 2$ orang dan tipe keluarga inti.

Karakteristik responden merupakan usia matang secara psikologis sudah siap dalam merawat dan mengasuh anak-anak yang dimiliki. Pendidikan yang tinggi artinya memiliki pengetahuan yang baik serta tipe keluarga ini memperkuat terbentuk pola asuh yang mendukung perkembangan anak, tidak ada campur tangan orang ketiga (nenek/kakek ataupun saudara lainnya). Responden yang bekerja serta jumlah anak $\leq 2$ orang memberikan waktu yang cukup untuk berinteraksi bersama anak 
secara aktif di rumah (quality time) dan mendampingi anak saat bermain gadget sehingga anak merasakan kasih sayang dan perhatian dari orangtuanya yang berpengaruh terhadap perkembangan anak. Anak dapat berkembang sesuai usia dan dapat mencapai target perkembangan nya.

\section{f. Hubungan antara frekuensi penggunaan gadget dengan perkembangan sosial anak}

Hasil penelitian ini menunjukkan bahwa sebagian besar anak yang mengalami perkembangan sosial kurang dari rata-rata adalah anak yang cenderung memiliki kebiasaan bermain gadget lebih dari 1 kali sehari dengan waktu penggunaan lebih dari 60 menitsebanyak 9 anak (16.9\%) dengan lamanya $>60$ '/hari sebanyak 20 anak (37.7\%). Hal ini dikarenakan pemakaian gadget yang terlalu lama dapat berdampak bagi kesehatan anak selain radiasinya yang berbahaya, penggunaan gadget yang terlalu lama dapat mempengaruhi tingkat agresif anak. Selain itu anak menjadi tidak peka terhadap lingkungan di sekelilingnya. Anak terlalu asyik dengan gadgetnya berakibat lupa untuk berinteraksi ataupun berkomunikasi dengan orang sekitar maupun keluarga dan itu akan berdampak buruk bagi perkembangan sosial anak (Gunawan MAA, 2017).
Hasil penelitian Novitasari w dan Khotimah N(2016) menunjukkan bahwa apabila tidak ada penggunaan gadget pada anak usia 5-6 tahun maka interaksi sosial anak akan tetap berkembang. Tetapi jika ada penambahan 1 hari penggunaan gadget, maka nilai interaksi sosial bertambah 0,159 artinya penggunaan gadget akan berpengaruh terhadap interaksi sosial anak.

Berdasarkan data didapatkan bahwa waktu terbanyak yang dihabiskan anak untuk bermain gadget dalam kategori normal yaitu 1 kali sehari dengan waktu penggunaan kurang dari 60 menit. Hal ini sesuai dengan ketentuan dari asosiasi dokter anak Amerika Serikat (Hasanah M, 2017). Tetapi ada 9 anak (16.9\%) waktu yang digunakan bermain gadget lebih dari 1 kali sehari dengan waktu penggunaan lebih dari 60 menit. Dilihat dari sebagian besar responden bekerja diluar rumah namun saat berada di rumah menghabiskan waktu dengan anaknya (quality time) sehingga anak tetap dapat berinteraksi langsung secara aktif kepada orangtuanya meskipun mereka menggunakan gadget sehingga perkembangan anak tetap terpantau oleh orangtuanya.

Pendidikan tinggi pada sebagian besar responden juga mendukung terbentuknya pola asuh yang mendukung perkembangan 
anak sesuai usia salah satunya adanya aturan dalam menggunakan gadget. Tipe keluarga yang semuanya keluarga inti serta jumlah anak yang $\leq 2$ orang dapat menambah kualitas interaksi antara anak dan orangtua selama di rumah. Orangtua lebih fokus dan terarah untuk mendampingi anaknya saat bermain gadget dan bermain bersama orangtua secara aktif di rumah sehingga perkembangan anak dapat tercapai sesuai usia dan maksimal.

\section{Simpulan}

Berdasarkan penelitian ini, maka dapat dibuat kesimpulan yaitu tidak ada hubungan yang bermakna secara statistik antara lama dan frekuensi penggunaan gadget dengan perkembangan sosial anak prasekolah di TK Islam Al Irsyad 02 Cilacap Tahun 2018.

Setiap orangtua pasti menginginkan yang terbaik untuk anak-anaknya. Namun, pengetahuan, latar belakang dan pengalaman mendorong setiap tindakan dan perbuatan. Berdasarkan hasil penelitian ini, maka penulis mengajukan saran bahwa perlu adanya pengawasan dari orangtua terhadap kegiatan anaknya dalam pemakaian gadget.

\section{Daftar Pustaka}

Al Fitri S, 2018. Gambaran Peran Orangtua Pada Anak Prasekolah
Yang Menggunakan Gadget di TK Islam Al Irsyad 01 Cilacap. STIKES Al Irsyad Al Islamiyyah. Tidak Dipublikasikan

Chikmah AM, Fitrianingsih D, 2018. Pengaruh Durasi Penggunaan Gadget Terhadap Masalah Mental Emosional Anak Pra Sekolah di TK Pembina Kota Tegal. Jurnal Siklus Vol.07 No.02 Juni 2018

Delima R, Arianti NK \& Pramudyawardani B, 2015. Identifikasi Kebutuhan Pengguna Untuk Aplikasi Permainan Edukasi Bagi Anak Usia 4-6 Tahun. Jurnal teknik informatika dan sistem informasi Vol.1 No.1

Gunawan MAA, 2017. Hubungan Durasi Penggunaan Gadget Terhadap Perkembangan Sosial Anak Prasekolah di TK PGRI 33 Sumurboto Banyumanik Semarang. Tidak dipublikasikan, UNDIP

Hasanah M, 2017. Pengaruh gadget terhadap kesehatan mental anak. Indonesian Journal of Islamic Early Childhood Education Vol.2 No. 2 Desember 2017

Hidayati, 2013. Pengaruh Penggunaan Gadget Terhadap Perkembangan Psikologis Anak Usia Dini. Skripsi

Kozier dkk, 2011. Buku Ajar Fundamental Keperawatan edisi 7 Vol.1,Jakarta : EGC

Laili U, 2017. Influence OfGadgetOn Social Personal OfEarly 
Childhood. Proceeding of Surabaya International Health Conference, Juli 13-14, 2017

Marsal A \& Hidayati F, 2017, Pengaruh Smarphone Terhadap Pola Interaksi Sosial Pada Anak Balita Di Lingkungan Keluarga Pegawai UIN Sultan Syarif Kasim Riau. Jurnal Ilmiah Rekayasa dan Manajemen Sistem Informasi, Vol.3 No.1 Februari 2017 Hal. 78 84

Nabila, Sarah dan Lisiswanti, Rika, 2017. Dampak Eksposur Layar Monitor Terhadap Gangguan Tidur Daan Tingkat Obesitas Pada Anak-Anak. Jurnal Majority, Vol.6 No.2 Maret 2017 Hal.73-78

Novitasari W \& Khotimah N, 2016. Dampak Penggunaan Gadget Terhadap Interaksi Sosial Anak Usia 5-6 Tahun. Jurnal PAUD Teratai Vol.05 No.03 Tahun 2016:182-186

Pangastuti R, 2017. Fenomena Gadget Dan Perkembangan Sosial Bagi Anak Usia dini. Indonesian Journal of Islamic Early Childhood Education Vol.2 No.2 Desember 2017

Pangestu, 2014. Statistik Induktif. Yogyakarta : BPF

Potter P \& Perry AG, 2009. Fundamental of Nursing $\left(7^{\text {th }} \mathrm{Ed}\right)$ Vo.1 Mosby : Elsevier Inc

Sapardi VS, 2018. Hubungan Penggunaan Gadget Dengan Perkembangan Anak Usia Prasekolah di PAUD/TK Islam
Budi Mulia. Menara Ilmu Vol.XII Jilid II No.80 Februari 2018

Soetjiningsih, Ranuh, Gde, 2015. Tumbuh Kembang Anak Edisi 2, Jakarta : EGC

Warisyah Y, 2015. Pentignya "Pendampingan Dialogis" Orangtua Dalam penggunaan gadget pada anak usia dini. Makalah disajikan dalam Prosiding Seminar Nasional Pendidikan di FKIP Universitas Muhamadiyah Ponorogo, 7 November $2015 \quad$ (online) (http://semnas.fkip.umpo.ac.id/wp -content/uploads/2015/12/014Yusmi-W.pdf), diakses 18 Agustus 2018

Widiawati I, Sugiman H, Edy, 2014. Pengaruh Penggunaan Gadget Terhadap Daya Kembang Anak. Jakarta : Universitas Budi Luhur. Diakses tanggal 10 September 2018

Wiguna, 2013. Mengenali Dan Memahami Tumbuh Kembang Anak. Jogjakarta : Katahari

Wijanarko J. 2017. Pengaruh Pemakaian Gadget, Perilaku Anak Terhadap Kemampuan Anak di Taman Kanak-kanak Happy Holy Kids Jakarta. Jurnal Institut Kristen Borneo, 2017. journal.institutkristenborneo.ac.id (diperoleh tanggal 26 Januari 2018)

Wong DL, Marlyn HE, David W, Marilyn W, Patricia S, 2009. Buku Ajar Keperawatan Pediatric (ed 6.Vol.1).Jakarta : EGC 
Yland J, Guan S, Emauele E, Hale L. Interactive $V s$ Passive Screen Time And Nighttime Sleep Duration Among School-Aged Children. Sleep Health. 2015; 1(3):191-6 